\title{
LA-UR-16-21653
}

Approved for public release; distribution is unlimited.

Title: $\quad$ Engineered Option Treatment of Remediated Nitrate Salts: Surrogate Batch-Blending Testing

Author(s): $\quad$ Anast, Kurt Roy

Intended for: Report

Issued: 
Disclaimer:

Los Alamos National Laboratory, an affirmative action/equal opportunity employer,is operated by the Los Alamos National Security, LLC for the National NuclearSecurity Administration of the U.S. Department of Energy under contract DE-AC52-06NA25396. By approving this article, the publisher recognizes that the U.S. Government retains nonexclusive, royalty-free license to publish or reproduce the published form of this contribution, or to allow others to do so, for U.S. Government purposes. Los Alamos National Laboratory requests that the publisher identify this article as work performed under the auspices of the U.S. Departmentof Energy. Los Alamos National Laboratory strongly supports academic freedom and a researcher's right to publish; as an institution, however, the Laboratory does not endorse the viewpoint of a publication or guarantee its technical correctness. 
March 9, 2016

\section{Engineered Option Treatment of Remediated Nitrate Salts: Surrogate Batch-Blending Testing}


Prepared by Kurt R. Anast

Associate Directorate Environmental Management

Los Alamos National Laboratory, operated by Los Alamos National Security, LLC, for the U.S. Department of Energy (DOE) under Contract No. DE-AC52-06NA253 and under DOE Office of Environmental

Management Contract No. DE-EM0003528, has prepared this document. The public may copy and use this document without charge, provided that this notice and any statement of authorship are reproduced on all copies. 


\section{EXECUTIVE SUMMARY}

This report provides results from batch-blending test work for remediated nitrate salt (RNS) treatment. Batch blending was identified as a preferred option for blending RNS and unremediated nitrate salt (UNS) material with zeolite to effectively safe the salt/Swheat material identified as ignitable (U.S. Environmental Protection Agency code D001). Blending with zeolite was the preferred remediation option identified in the Options Assessment Report ${ }^{1}$ and was originally proposed as the best option for remediation by Clark and Funk in their report, Chemical Reactivity and Recommended Remediation Strategy for Los Alamos Remediated Nitrate Salt (RNS) Wastes ${ }^{2}$ and also found to be a preferred option in the Engineering Options Assessment Report: Nitrate Salt Waste Stream Processing. ${ }^{3}$

This test work evaluated equipment and recipe alternatives to achieve effective blending of surrogate waste with zeolite. An 8-qt Kitchen Aid blender was used to blend zeolite and surrogate RNS waste to ensure a well-blended product could be prepared from a range of surrogate formulations. Surrogate blends of salt and Swheat were prepared with dyed Swheat and colored sodium chloride rock salt. These color-enhanced surrogates provided a means to visually evaluate the effectiveness of blending the surrogate with zeolite. The surrogate feed material for the test work was formulated to have a range of moisture and salt content to ensure the surrogates would bound the RNS waste characteristics expected to be found in the candidate drums.

Tests with salt combined with Waste Lock 770 were also carried out. Waste Lock 770 was combined with nitric acid in the laboratory and then blended with zeolite using the same process and blending operation used for surrogates formulated with Swheat. Comparable tests were performed with salt combined with water to identify any observable differences with the baseline nitric acid test, but none were observed. All further Waste Lock 770 testing was performed with water-saturated salt.

The 8-qt Kitchen Aid mixer (Model KSMC895ER) was found to effectively blend the entire range of surrogates RNS formulations with zeolite. Similar results were found with surrogates of salt and Waste Lock 770. The 8-qt Kitchen Aid model fits easily into the Waste Characterization Reduction and Repackaging Facility (WCRRF) glovebox, allows for two blenders to be used simultaneously, is relatively easy to install in the glovebox or remove if required, easy for one person to operate, and has a 2-gal volume mixing bowl. A mixing duration of $30 \mathrm{~s}$ to $1 \mathrm{~min}$ is adequate to get a well-blended zeolite and surrogate product. The resulting blend easily dumps out of the bowl when the side is tipped and tapped, resulting in $95 \%$ of the contents discharging. To minimize dose to the operator and to best contain the materials during blending, a slightly modified bowl with a cover will be fabricated for the RNS blending process. The bowl will have an expanded upper lip as well as a slip-on cover. These adjustments will ensure the material is enclosed during processing and will reduce possible dose to workers during the blending operation.

A recipe and process were identified based upon testing a range of surrogates and an examination of the resulting blend with zeolite. The batch-blending tests were designed to simulate the test work conducted at Southwest Research Institute (SWRI). The final blending recipe will be identified upon conclusion of SWRI nitrated surrogate testing. The intent is to verify that large-scale volume $(6 \mathrm{qt})$ blending of colored Swheat, salt, and zeolite in ratios tested at SWRI will provide a well-blended and remediated product for

\footnotetext{
${ }^{1}$ Robinson, B.A., and P.A. Stevens, December 16, 2015. "Options Assessment Report: Treatment of Nitrate Salt Waste at Los Alamos National Laboratory, Revision 1," Los Alamos National Laboratory document LA-UR-15-27180, Los Alamos, New Mexico.

${ }^{2}$ Clark, D.L., and D.J. Funk, February 17, 2015. "Chemical Reactivity and Recommended Remediation Strategy for Los Alamos Remediated Nitrate Salt (RNS) Wastes," Los Alamos National Laboratory document LA-UR-15-22393, Los Alamos, New Mexico.

${ }^{3}$ Anast, K.R., November 2015. "Engineering Options Assessment Report: Nitrate Salt Waste Stream Processing," Los Alamos National Laboratory document LA-UR-15-28900, Los Alamos, New Mexico.
} 
the entire range of possible RNS physical waste compositions. The blending process was effective over the following ranges:

- Swheat moisture content: $25 \mathrm{wt} \%$ to $60 \mathrm{wt} \%$

- RNS surrogate salt composition: 22 vol\% to 50 vol\%

- RNS surrogate-to-zeolite blend volume ratio: 1:2 to 1:4

- Water addition rate (RNS surrogate to water volume ratio): 1:1 to 1:0.5

Testing showed that a single recipe could be followed to provide (1) water to achieve a soupy mixture and dissolve salts in the RNS waste and (2) zeolite to absorb the RNS solution and remediate the Swheat material. The amount of zeolite will be confirmed with testing at SWRI on nitrated surrogate blends. The ratios of ingredients on a volume basis are

- 1 volume RNS waste (Swheat and nitrate salts),

- 0.65 volume water, and

- 2.5 volumes zeolite.

The recommended steps for the blending process and the recipe for the 8-qt Kitchen Aid mixer are as follows:

1. Add 1.15 qt warm water to bowl

2. Add 1.75 qt RNS waste

3. Blend on speed setting 4 for 3 min

4. Add 2.20 qt of zeolite

5. Blend on speed setting 8 for $10 \mathrm{~s}$

6. Reduce speed to setting 3

7. Add 2.20 qt of zeolite

8. Blend for $30 \mathrm{~s}$

This recipe includes the addition of water used to first mix with the RNS waste. The water acts to moisten the Swheat material and creates a soupy consistency that is easier to blend into the zeolite. It also provides a means to dissolve salts and aids in desorbing or wetting salts already contained in the Swheat. The zeolite addition rate provides sufficient zeolite for water absorption and remediating the nitrate salts and will be verified by SWRI tests. The recipe can be used for dry Swheat and salt, Swheat used to absorb free liquid found in the RNS parent drums, salt blended with Waste Lock 770, or a blend of these. 


\section{CONTENTS}

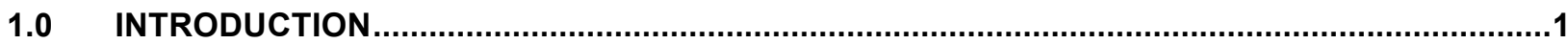

1.1 Objective

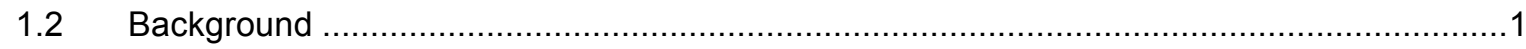

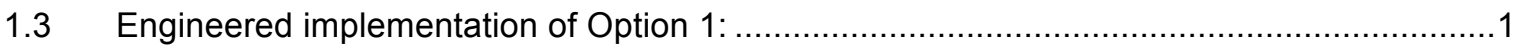

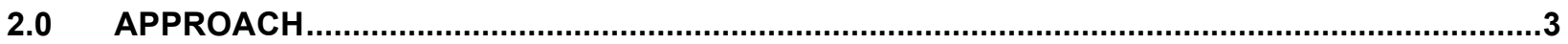

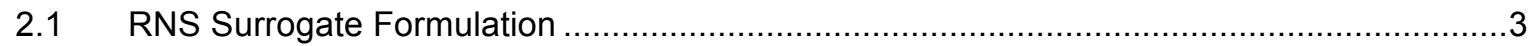

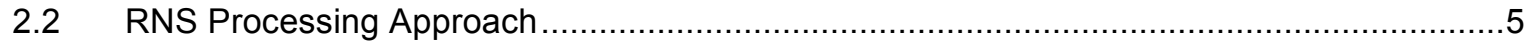

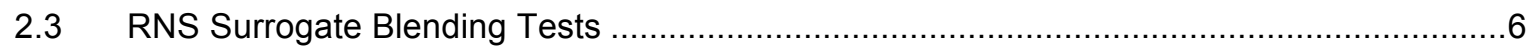

2.3.1 Step 1: RNS Waste Dissolution Step .......................................................

2.3.2 Steps 2 and 3 Tests: Addition of Zeolite........................................................

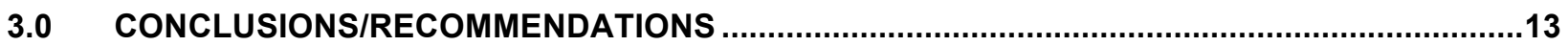

\section{Figures}

Figure 1. Samples of zeolite, Swheat, rock salt, and dye used for tests .................................... 3

Figure 2. Sample of dyed Swheat and purple rock salt—surrogate RNS material ....................... 4

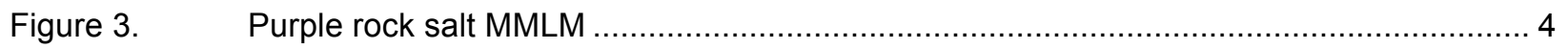

Figure 4. Surrogate waste formulations for zeolite-blend testing .......................................... 5

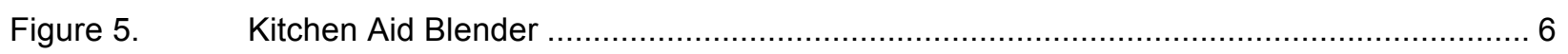

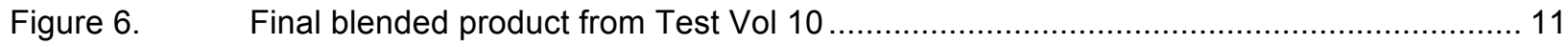

Figure $7 \quad$ Surrogate Waste Lock 770 and salt (3:1 volume ratio) ............................................. 12

Figure $8 \quad$ Waste Lock 770 surrogate waste blended with zeolite (Test WL 13) ........................... 12

\section{Tables}

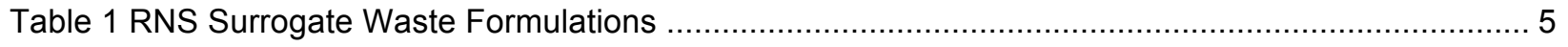

Table 2 Solubility of Various Salts in Water and Volume of Water Required to Dissolve Salt in Various

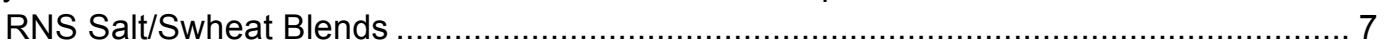

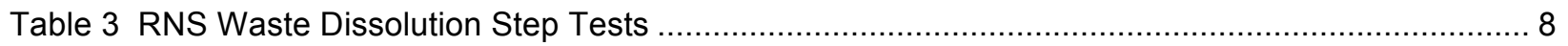

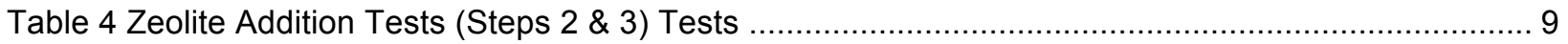




\section{Acronyms and Abbreviations}

DOE Department of Energy

EPA Environmental Protection Agency (U.S.)

LANL Los Alamos National Laboratory

LLW low-level waste

MMLM Merlin Melts Like Magic

NMED New Mexico Environmental Department

RNS remediated nitrate salts

SWB standard waste boxes

SWRI Southwest Research Institute

UNS unremediated nitrate salts

WCRRF Waste Characterization Reduction and Repackaging Facility

WIPP Waste Isolation Pilot Plant

WL Waste Lock 


\section{$1.0 \quad$ INTRODUCTION}

\subsection{Objective}

The primary objective of conducting batch-blending tests is to identify processing equipment, an ingredient recipe, and the process steps for safing remediated nitrate salt (RNS) waste contained in 60 on-site drums at Los Alamos National Laboratory (LANL). The treated RNS and UNS waste will be packaged and shipped to the Waste Isolation Pilot Plant (WIPP) for disposal. Batch-blending tests on RNS surrogate material will be used to evaluate blending equipment and ingredient information for a processing recipe.

\subsection{Background}

This report documents the process development of Option 1 (modification of Option 1) for use in the treatment for the RNS and UNS waste containers at LANL. Modified Option 1 is the dissolution of the nitrate salts in water followed by blending of the drum waste (Swheat and nitrate salt) with zeolite. For the UNS waste, this consists of dissolving nitrate salts in water and then adding zeolite to absorb the salt solution. For RNS waste, the nitrate salt/Swheat material would be mixed first with water and then blended with zeolite to absorb the salt solution and remediate the Swheat material.

This engineered implementation of Option 1 treats the containerized material in a manner that renders the waste safe and suitable for transport and final disposal in the WIPP repository, under specifications listed in the WIPP Waste Acceptance Criteria (DOE/CBFO, 2013). LANL recognizes that the results must be thoroughly vetted with the New Mexico Environment Department (NMED) and that a modification to the LANL Hazardous Waste Facility Permit is a necessary step before implementation of this or any treatment option. Likewise, facility readiness and safety basis approvals must be received from the Department of Energy (DOE). This report presents LANL's process development and testing of modified Option 1, and documentation of the process for determining the recommended treatment option for the RNS and UNS wastes. The process will be followed using nitrated salts mixed with Swheat at Southwest Research Institute (SWRI) to prepare samples for confirmatory evaluation to ensure the zeolite blended product passes ignitability and spontaneous combustion tests.

After the release of radioactivity from the WIPP on February 14, 2014 and the subsequent recognition that the breached drum was a RNS waste drum processed at LANL (Drum 68660), LANL took a number of precautionary steps to protect workers, the public, and the environment. Drums stored at LANL continue to be maintained in isolated storage. Monitoring results are reported to the NMED under the LANL Nitrate Salt Bearing Waste Container Isolation Plan (Isolation Plan: LANL, 2014). Drums are currently stored under a High Efficiency Particulate Air filtration system and the temperature controls provided by the building, with active fire suppression systems. Monitoring of the drums consists of visual inspections, daily temperature measurements of the standard waste boxes (SWBs) containing the RNS waste drums, and periodic sampling and analysis of the headspace gases within these SWBs. This configuration of the RNS wastes at LANL represents the initial state for a subsequent treatment option being considered in this Addendum.

The report describes the process development of Option 1, one option of fourteen potential treatment options, recommended to permanently treat the combination of nitrate salt and Swheat drum waste. This report documents a small-scale, batch blending study conducted to ensure techniques are adequate to render the waste material treatable.

\subsection{Engineered implementation of Option 1:}

The focus of these tests is to identify the best equipment, process, and recipe to prepare a well-blended product that meets the waste acceptance criteria for disposal WIPP. The RNS drums that remain at LANL 
include 60 identified drums, of which 56 were repackaged with an organic kitty litter and 4 were repackaged with Waste Lock 770 , a solid, granular superabsorbent polymer. This cross-linked polyacrylate material swells and absorbs many times its weight in aqueous solutions. Waste Lock 770 has been engineered to absorb under pressure and has properties that make it ideally suited for the absorption and solidification of low-level waste (LLW) and other types of waste sludges. Swheat Scoop, primarily a wheat-based organic kitty litter, was added to the unremediated nitrate salt (UNS) waste during repackaging to absorb free liquids and remediate the ignitability characteristic of the nitrate salts. The resulting mixture was repackaged in daughter drums that became the RNS waste stream.

Swheat was found to increase the hazard associated with the UNS waste by creating a potential for exothermic chemical reactions ${ }^{1}$. After a release at WIPP from a stored LANL RNS drum containing Swheat, LANL initiated steps to isolate all remaining RNS waste drums located at LANL. The drums were overpacked in SWBs and placed in a Permacon, in Dome 375, at Area G, located in Technical Area 54. The RNS drums are being stored in a temperature-controlled environment to mitigate the oxidizing behavior of the waste in the drums. LANL designated all remaining RNS drums at LANL as "ignitable," assigning U.S. Environmental Protection Agency (EPA) Hazardous Waste Number D001 after independent reactivity testing on surrogate samples containing Swheat and sodium nitrate salt ${ }^{2}$. Those drums containing free liquid have also been assigned an EPA code of D002 (corrosive).

An options assessment report and an engineering options assessment report ${ }^{3}$ were prepared to evaluate various treatment options for the RNS and UNS waste streams to remove their hazardous characteristics, in response to a New Mexico Environment Department-issued Administrative Order. This assessment identified five candidate treatment options for remediation of both RNS and UNS drums at LANL. The preferred option was dry blending with zeolite as the primary unit operation for remediating the drums. This test work provides an evaluation of batch blending that could be effectively conducted inside a glovebox and identifies equipment, process steps, and a recipe for achieving a well-blended zeolite and RNS waste for disposal at WIPP.

Ongoing testing at SWRI with surrogate nitrate salt material will provide analytical verification of the zeolite-blended surrogates (SW-846, Test Method 1030, SW-846, Test Method 1050, UN DOT 0.1 and 0.2 oxidizer tests, and 9095B Paint Filter tests) that blending RNS waste with zeolite can (1) effectively deactivate the ignitable and corrosive characteristics of the RNS waste, (2) produce a product that no longer carries the D001 or D002 hazardous waste number designations, and (3) meet WIPP waste acceptance criteria. This report identifies how to achieve an acceptable blended product.

\footnotetext{
${ }^{1}$ Robinson, B.A., and P.A. Stevens, December 16, 2015. "Options Assessment Report: Treatment of Nitrate Salt Waste at Los Alamos National Laboratory, Revision 1," Los Alamos National Laboratory document LA-UR-15-27180, Los Alamos, New Mexico.

${ }^{2}$ Clark, D.L., and D.J. Funk, February 17, 2015. "Chemical Reactivity and Recommended Remediation Strategy for Los Alamos Remediated Nitrate Salt (RNS) Wastes," Los Alamos National Laboratory document LA-UR-15-22393, Los Alamos, New Mexico.

${ }^{3}$ Anast, K.R., November 2015. "Engineering Options Assessment Report: Nitrate Salt Waste Stream Processing," Los Alamos National Laboratory document LA-UR-15-28900, Los Alamos, New Mexico.
} 


\section{$2.0 \quad$ APPROACH}

To evaluate the effectiveness of batch blending zeolite with RNS waste, the following steps were followed:

1. Prepare a surrogate RNS waste that can be tracked visually

2. Prepare a range of surrogate wastes that have moisture and salt contents that will bound the waste likely to be found in the 60 RNS drums

3. Conduct blending tests on varying recipes of waste, zeolite, and water

4. Determine the blending speed, duration of blend, volume of material, and ingredients that provide a well-blended zeolite RNS waste product and maximizes batch volume.

\subsection{RNS Surrogate Formulation}

Surrogate RNS waste was prepared from Swheat and sodium chloride rock salt. Figure 1 shows the zeolite, Swheat, rock salt, and dye used for all tests.

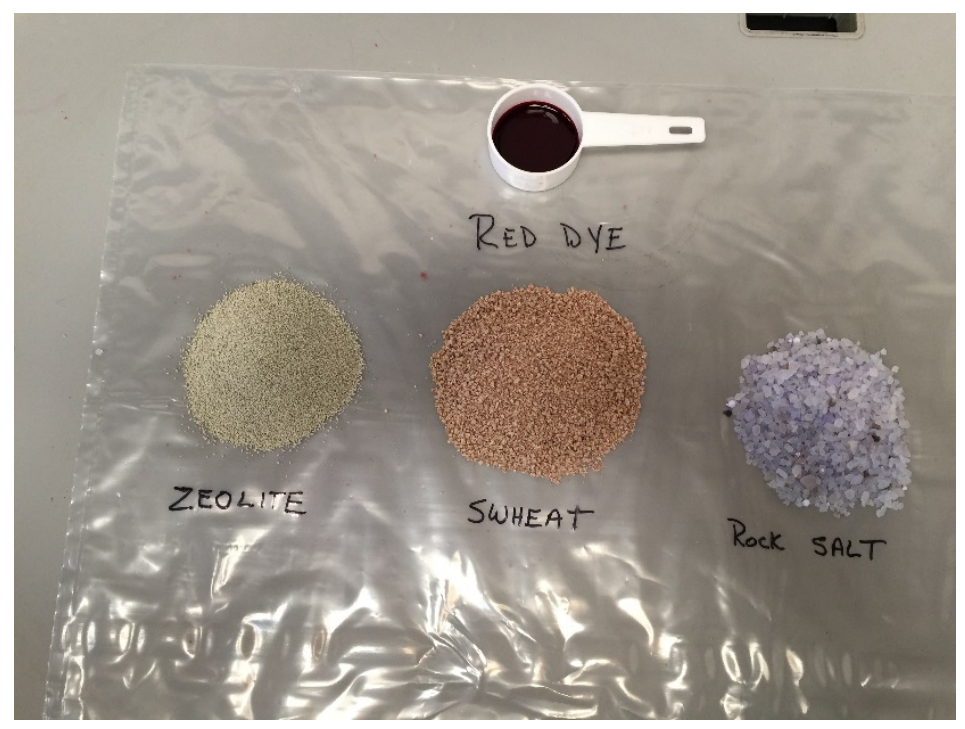

Figure 1. Samples of zeolite, Swheat, rock salt, and dye used for tests

Swheat was colored red with red food coloring by blending 1 volume of water, 1 capful of red food coloring, and 9 volumes of Swheat kitty litter. The resulting Swheat contained approximately $25 \%$ moisture and was a dry-appearing material. Figure 2 shows the Swheat after it was dyed red and combined with the rock salt. The red-dyed Swheat and purple rock salt were used in all batch-blending test work. 


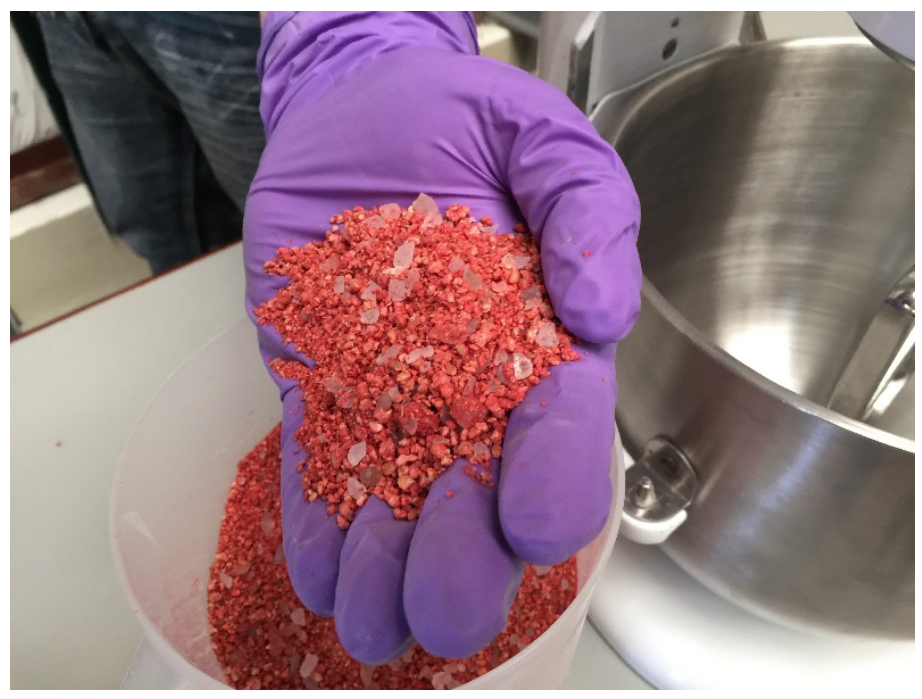

Figure 2. Sample of dyed Swheat and purple rock salt-surrogate RNS material

Rock salt that was dyed purple was purchased to prepare the RNS surrogate waste for batch-blending tests. The product used was Merlin Melts Like Magic (MMLM) and is shown in Figure 3.

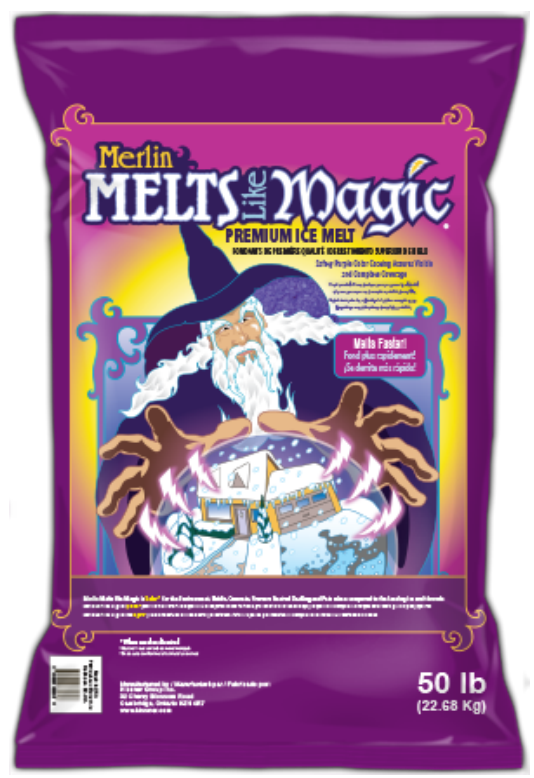

Figure 3. Purple rock salt MMLM

Dyed Swheat and purple rock salt were then blended together in a Kitchen Aid blender by blending predetermined volumes of each for $1 \mathrm{~min}$. Six blends were prepared and are detailed in Table 1 and shown in Figure 4.

RNS surrogate blends were prepared by blending various volumetric ratios of ingredients together to produce material that would bound the physical properties of the RNS waste likely to be found in the candidate RNS drums. Moisture content and salt loading are the two primary variables that were adjusted. A dry product simulates the salt/Swheat material, and the wet material simulates Swheat that absorbed liquid found in the UNS parent drum. 
Table 1

RNS Surrogate Waste Formulations

\begin{tabular}{|c|c|}
\hline Surrogate & $\begin{array}{c}\text { Swheat:Water:Salt } \\
\text { (vol. ratio) }\end{array}$ \\
\hline Dry/Low Salt & $9: 1: 2$ \\
\hline Dry/High Salt & $9: 1: 4.5$ \\
\hline Moist/Low Salt & $3: 1: 1$ \\
\hline Moist/High Salt & $3: 1: 1.5$ \\
\hline Wet/Low Salt & $2: 1: 0.5$ \\
\hline Wet/High Salt & $2: 1: 1$ \\
\hline
\end{tabular}

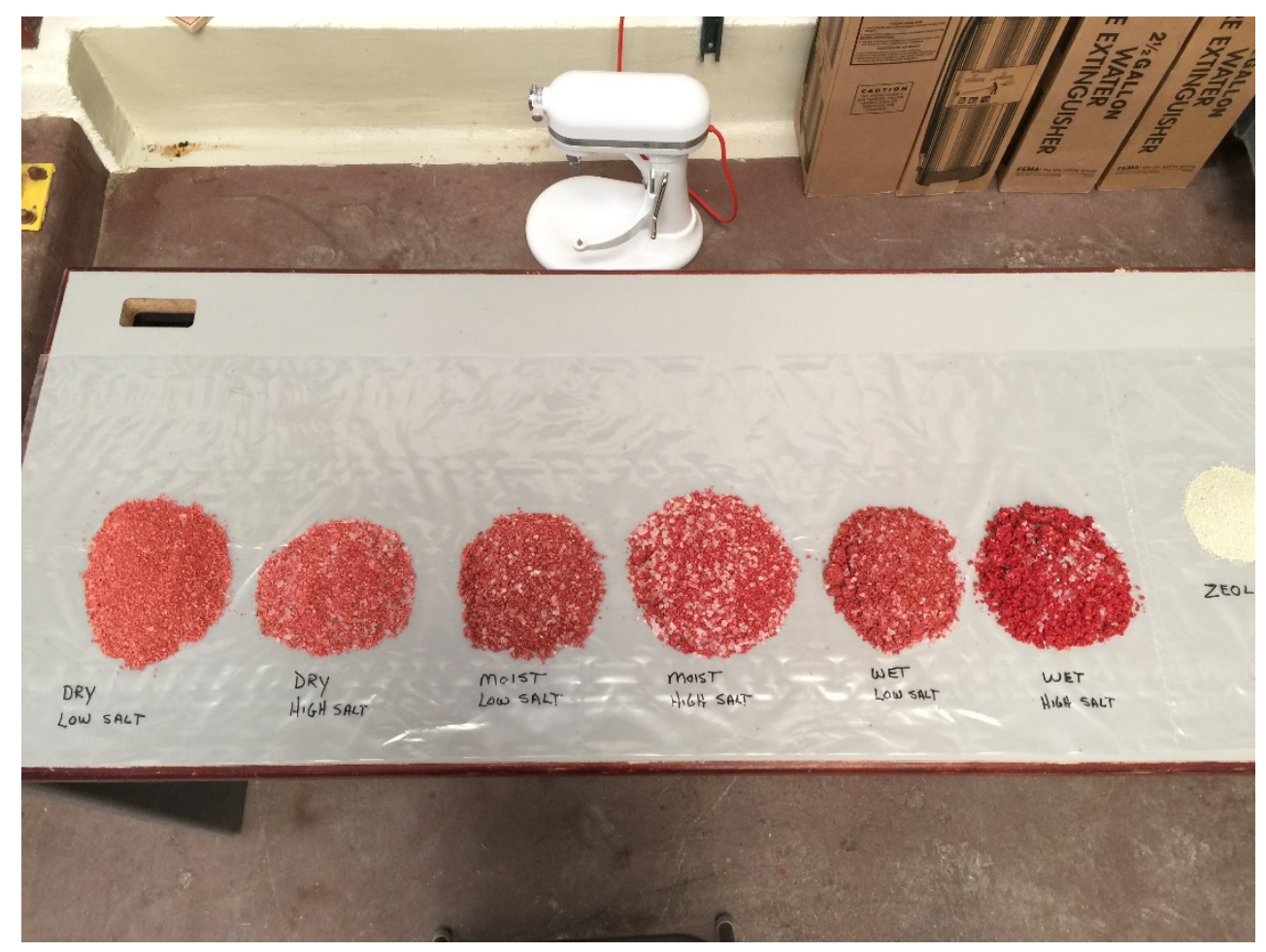

Figure 4. Surrogate waste formulations for zeolite-blend testing

\subsection{RNS Processing Approach}

Batch blending of RNS waste with zeolite occurs in a three-step process.

1. Blend RNS waste with water to achieve a soupy consistency that will more easily blend into zeolite and dissolve the available salt so it can be absorbed by zeolite

2. Add zeolite to the slurry to absorb any free liquid remediate the RNS waste

3. Blend until the ingredients are a homogenous mix 


\subsection{RNS Surrogate Blending Tests}

The batch-blending tests were carried out using an 8-qt Kitchen Aid blender, the largest commercially available model that fits into the Waste Characterization Reduction and Repackaging Facility (WCRRF) glovebox and is easily lifted and set in place. The parts exposed to liquid are stainless steel, which is the material of choice ${ }^{4}$ for nitric acid environment, which will accompany the RNS waste once dissolved. The blender is shown in Figure 5. The WCRRF glovebox will accommodate at least two blenders.

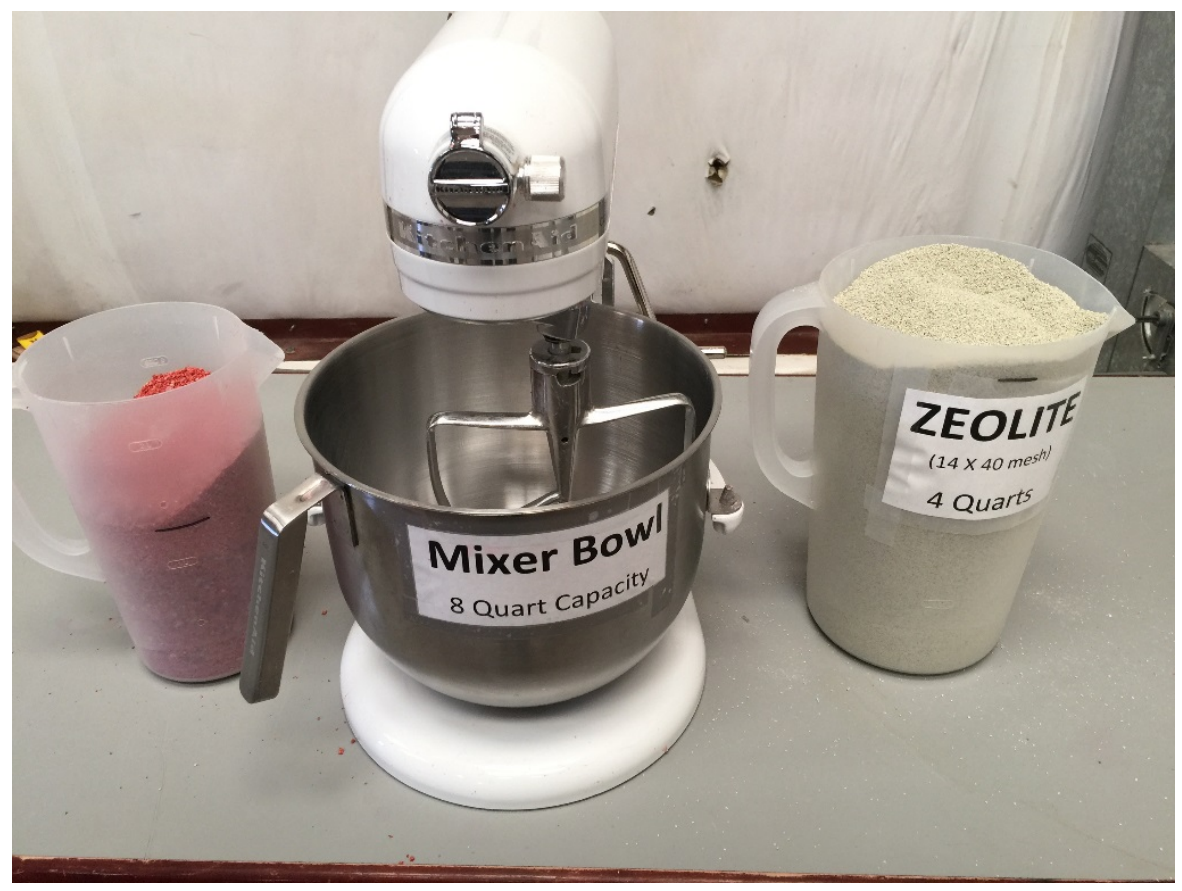

Figure 5. Kitchen Aid Blender

Surrogate RNS waste prepared with dyed Swheat and purple rock salt was blended with zeolite and water. A suite of tests was conducted to address a number of questions:

- The volume of water required (as a ratio of RNS waste surrogate) to achieve an acceptable consistency

- The blending time required to dissolve salt before zeolite is added

- The effectiveness of the blender at producing a homogenized product with Swheat well distributed throughout the zeolite matrix, independent of the RNS surrogate blend

- The speed of the blender and duration required for Step 1 and Step 3

- The ingredients for the recipe

- The ease of operation and manipulation for the glovebox configuration

\subsubsection{Step 1: RNS Waste Dissolution Step}

RNS waste dissolution includes combining water with RNS waste to achieve a soupy consistency to optimize blending the Swheat and salt into the zeolite and dissolve the salt. To evaluate this step, the

\footnotetext{
${ }^{4}$ Fontana, M.G., and N.D. Greene, 1967. Corrosion Engineering, McGraw-Hill Book Company, New York, New York.
} 
dry/high-salt surrogate was used to determine the amount of water and blending time necessary to dissolve the salt. The surrogate salt, MMLM, contains $80 \%$ sodium chloride, with the remaining $20 \%$ a blend of potassium chloride, magnesium chloride, and calcium magnesium acetate. MMLM is less soluble than any of the major nitrate salts found in the RNS waste material. See Table 2.

The estimated volume of water required for salt dissolution per liter of waste is presented in Table 2 . (Approximately $590 \mathrm{~g}$ of SWRI surrogate salt is found in a liter of surrogate RNS waste blended at a 2:1 volume ratio of Swheat to salt.) Table 2 compares the amount of water required to dissolve the salt found in $1 \mathrm{~L}$ of RNS waste at three different volume ratios of Swheat to salt. The amount of water required relates both to the solubility of the salt and the density because the Swheat:salt ratio is volumetric. Based upon the estimated ratio of each nitrate salt expected in the RNS drums ${ }^{5}$, the water required for complete dissolution of the RNS salts is $0.79 \mathrm{~L}$ for a 2:1 volumetric Swheat:salt ratio and $0.64 \mathrm{~L}$ for a 3:1

Swheat:salt volumetric ratio.

Because nitrate salts require less water for dissolution compared with the surrogate sodium chloride, the tests will focus on both salt dissolution and consistency of the slurry. Therefore, the time required to dissolve sodium chloride in the surrogate samples should provide an indication of the required mix time for RNS waste material. Tests at SWRI will provide guidance on the effectiveness of dissolving nitrate salts during this step.

Table 2

Solubility of Various Salts in Water and Volume of Water Required to Dissolve Salt in Various RNS Salt/Swheat Blends

\begin{tabular}{|c|c|c|c|c|}
\hline \multirow[b]{2}{*}{ Salt } & \multirow{2}{*}{$\begin{array}{c}\text { Pure Salt } \\
\begin{array}{c}\text { Solubility@ } 2{ }^{\circ} \mathrm{C} \\
(\mathrm{g} / \mathrm{L})\end{array}\end{array}$} & \multicolumn{3}{|c|}{ Water Required to Dissolve Salt in RNS } \\
\hline & & $\begin{array}{l}\text { 1:1 Swheat:salt } \\
\left(\mathrm{L} \mathrm{H}_{2} \mathrm{O} / \mathrm{L} \text { Waste }\right)\end{array}$ & $\begin{array}{l}\text { 2:1 Swheat:salt } \\
\text { ( } \mathrm{L} \mathrm{H}_{2} \mathrm{O} / \mathrm{L} \text { Waste) }\end{array}$ & $\begin{array}{l}\text { 3:1 Swheat:salt } \\
\text { ( } \mathrm{L} \mathrm{H}_{2} \mathrm{O} / \mathrm{L} \text { Waste) }\end{array}$ \\
\hline MMLM & $370(2.16)^{*}$ & 2.91 & 1.94 & 1.46 \\
\hline SWRI Surrogate Salt Blend & $684(1.76)^{*}$ & 1.05 & 0.79 & 0.64 \\
\hline $\mathrm{Mg}\left(\mathrm{NO}_{3}\right)_{2} * 6 \mathrm{H}_{2} \mathrm{O}(22 \%)$ & 625 & 1.07 & 0.71 & 0.53 \\
\hline $\mathrm{Ca}\left(\mathrm{NO}_{3}\right)_{2} * 4 \mathrm{H}_{2} \mathrm{O}(5 \%)$ & 1290 & 0.78 & 0.52 & 0.39 \\
\hline $\mathrm{NaNO}_{3}(3 \%)$ & 912 & 1.25 & 0.83 & 0.62 \\
\hline $\mathrm{Fe}\left(\mathrm{NO}_{3}\right)_{3} * 9 \mathrm{H}_{2} \mathrm{O}(3 \%)$ & 1500 & 0.56 & 0.37 & 0.28 \\
\hline $\mathrm{Al}\left(\mathrm{NO}_{3}\right)_{3} * 9 \mathrm{H}_{2} \mathrm{O}(46 \%)$ & 673 & 1.28 & 0.85 & 0.64 \\
\hline $\mathrm{Pb}\left(\mathrm{NO}_{3}\right)_{2}(3 \%)$ & 565 & 4.00 & 2.67 & 2.00 \\
\hline
\end{tabular}

* $=$ Density of salt

Six tests were completed using the dry/high salt surrogate to determine the impact of water volume, mixing speed, mixing duration, and water temperature on salt dissolution. The test conditions and resulting time required to dissolve the contained salt are presented in Table 3. A surrogate-to-water volume ratio of 1 resulted in a very thin, runny consistency that allowed the salt to dissolve fairly quickly but resulted in excessive liquid for the zeolite to absorb, an effect that becomes worse with a wetter surrogate. Surrogate-to-water ratios of 0.5 and 0.75 provided adequate liquid for most of the salt to dissolve, but as the volume approached the 0.5 ratio, the dissolution time became longer and the consistency of the mix was thicker. The mixing speed seemed to have some impact on the dissolution

\footnotetext{
${ }^{5}$ Source: Table 1: WB8 surrogate from SWRI Exhibit D for the SWRI contract.
} 
rate, but using a faster speed resulted in splashing of the contents. Water temperature had an expected impact of reducing the dissolution time. The final test examined the impact of the wet/high salt surrogate on salt dissolution. The dissolution time was similar to the dry/high salt surrogate; however, the resulting mix was of a thinner consistency.

The following conditions are recommended for the RNS waste dissolution step:

- RNS waste-to-water volume ratio: 1:0.65

- Mixer speed: 4 (with the addition of a lid during mixing)

- Blend duration: 3 min

Table 3

RNS Waste Dissolution Step Tests

\begin{tabular}{|c|c|c|c|c|}
\hline Surrogate Type & $\begin{array}{c}\text { Surrogate:Water } \\
\text { Volume Ratio }\end{array}$ & Blend speed & $\begin{array}{c}\text { Water Temp } \\
\text { oC }\end{array}$ & $\begin{array}{c}\text { Time (min) } \\
\text { Salt Dissolution }\end{array}$ \\
\hline Dry/High Salt & $1: 1$ & 3 & 10 & $\mathbf{2 . 5}$ \\
\hline Dry/high Salt & $1: 0.75$ & 3 & 10 & $\mathbf{3 . 0}$ \\
\hline Dry High Salt & $1: 0.5$ & 3 & 10 & $\mathbf{3 . 5}$ \\
\hline Dry high Salt & $1: 0.66$ & 4 & 10 & $\mathbf{3 . 0}$ \\
\hline Dry High Salt & $1: 0.66$ & 4 & 37 & $\mathbf{2 . 0}$ \\
\hline Wet/High Salt & $1: 066$ & 4 & 37 & $\mathbf{2 . 0}$ \\
\hline
\end{tabular}

\subsubsection{Steps 2 and 3 Tests: Addition of Zeolite}

Zeolite is added to absorb water, provide an inorganic matrix to hold the nitrate salts, and insulate the Swheat from interacting with available oxidizing salts. The zeolite used for these tests is from KMI Zeolite $^{6}$, located in Sandy Valley, Nevada, and is $14 \times 40$-mesh size. KMI zeolite is the same zeolite used in the blending tests at SWRI. Zeolite must be well mixed with the Swheat to effectively stabilize the waste and ensure it is no longer ignitable. The red-dyed Swheat provides a visual means to evaluate the effectiveness of producing a well-blended, homogeneous product.

The amount of zeolite required on a batch basis has not been determined yet. Previous test work at Energetic Materials Research and Testing Center in Socorro, New Mexico, indicates that nitrate salts can effectively be treated using a 1.2:1 volume ratio of zeolite-to-nitrate salts ${ }^{7}$ and zeolite is effective at mitigating the oxidizer properties of nitrates in waste surrogates. SWRI is currently engaged in test work that will provide additional guidance on the amount of zeolite required to ensure the RNS waste is no longer ignitable. SWRI blends samples by hand, mixing the salt/Swheat surrogate into the zeolite using a spatula. Use of the Kitchen Aid mixer provides a more consistent blending approach and will be used in the final SWRI process verification tests.

Table 4 presents the details of the 12 tests conducted, including the impact blend duration, blend speed, RNS surrogate characteristics, and zeolite volume on blending performance. The recommended

${ }^{6} \mathrm{KMI}$ Zeolite is typically $97 \%+$ pure clinoptilolite zeolite by weight.

${ }^{7}$ Walsh, G., March 2010. "Results of Oxidizing Solids Testing," Energetic Materials Research and Training Center Report FR 10-13, New Mexico Bureau of Mines \& Mineral Resources, New Mexico Institute of Mining and Technology, Socorro, New Mexico. 
conditions identified from Step 1 testing were used for all of the zeolite addition tests. The zeolite addition test conditions and resulting blend performance notes are shown in Table 4.

Step 1 conditions for all zeolite addition tests:

- RNS waste-to-water volume ratio: 1:0.65

* 1 qt of surrogate waste

* 0.65 qt of water

- Mixer speed setting: 4

- Blend duration: 3 min

Table 4

Zeolite Addition Tests (Steps 2 \& 3) Tests

\begin{tabular}{|l|c|c|c|l|}
\hline Blend \# & $\begin{array}{c}\text { Surrogate Waste } \\
\text { Type }\end{array}$ & $\begin{array}{c}\text { Zeolite } \\
\text { (qt) }\end{array}$ & $\begin{array}{c}\text { Blend } \\
\text { Duration } \\
\text { (min) }\end{array}$ & \multicolumn{1}{c|}{ Comments/Blend Speed } \\
\hline Moist 1 & Moist/Low Salt & 3 & 1.0 & $\begin{array}{l}\text { Added zeolite all at once and maintained speed @ 3 } \\
\text { Material was well blended and had a layer of buildup } \\
\text { on bottom/sides of bowl }\end{array}$ \\
\hline Moist 2 & Moist/Low Salt & 2 & 1.0 & $\begin{array}{l}\text { Added zeolite all at once and maintained speed @ 3 } \\
\text { Material was well blended and had a layer of buildup } \\
\text { on bottom/sides of bowl }\end{array}$ \\
\hline Moist 3 & Moist/Low Salt & 4 & 1.0 & $\begin{array}{l}\text { Added zeolite all at once and maintained speed @ 3 } \\
\text { Material was well blended and had a layer of buildup } \\
\text { on bottom/sides of bowl }\end{array}$ \\
\hline Moist 4 & Moist/Low Salt & 3 & 1.0 & $\begin{array}{l}\text { Added 1/2 zeolite and ran speed at 8 for 10 s, then } \\
\text { added remaining zeolite and blended at 3 for 1 min } \\
\text { Material was well blended and no Swheat build up on } \\
\text { bottom }\end{array}$ \\
\hline Dry 5 & Dry/High Salt & 3 & 1.0 & $\begin{array}{l}\text { Added 1/2 zeolite and ran speed at 8 for 10 s, then } \\
\text { added remaining zeolite and blended at 3 for 1 min } \\
\text { Material was well blended and no Swheat buildup on } \\
\text { bottom }\end{array}$ \\
\hline Wet 6 & Wet/High Salt & 3 & 1.0 & $\begin{array}{l}\text { Added 1/2 zeolite and ran speed at 8 for 10 s, then } \\
\text { added remaining zeolite and blended at 3 for 1 min } \\
\text { Material was well blended with no Swheat buildup on } \\
\text { bottom }\end{array}$ \\
\hline Moist 7 & Moist/High Salt & 2 & 1.0 & $\begin{array}{l}\text { Added 1/2 zeolite and ran speed at 8 for 10 s, then } \\
\text { added remaining zeolite and blended at 3 for 1 min } \\
\text { Material was well blended with no Swheat buildup on } \\
\text { bottom }\end{array}$ \\
\hline
\end{tabular}


Table 4 (continued)

\begin{tabular}{|c|c|c|c|c|}
\hline Blend \# & $\begin{array}{c}\text { Surrogate Waste } \\
\text { Type }\end{array}$ & $\begin{array}{c}\text { Zeolite } \\
\text { (Qt) }\end{array}$ & $\begin{array}{l}\text { Blend } \\
\text { Duration } \\
\text { (min) }\end{array}$ & Comments/Blend Speed \\
\hline Dry 8 & Dry/High Salt & 3 & 0.5 & $\begin{array}{l}\text { Added } 1 / 2 \text { zeolite and ran speed at } 8 \text { for } 10 \mathrm{~s} \text {, then } \\
\text { added remaining zeolite and blended at } 3 \text { for } 30 \mathrm{~s} \\
\text { Material was well blended with no Swheat buildup on } \\
\text { bottom }\end{array}$ \\
\hline Wet 9 & Wet/Low Salt & 4 & 0.5 & $\begin{array}{l}\text { Added } 1 / 2 \text { zeolite and ran speed at } 8 \text { for } 10 \mathrm{~s} \text {, then } \\
\text { added remaining zeolite and blended at } 3 \text { for } 30 \mathrm{sec} \\
\text { Material was well blended with no Swheat buildup on } \\
\text { bottom }\end{array}$ \\
\hline Vol 10 & Dry/High & 4.4 & $0.5^{\mathrm{a}}$ & $\begin{array}{l}\text { Added } 1 / 2 \text { zeolite and ran speed at } 8 \text { for } 10 \mathrm{~s} \text {, then } \\
\text { added remaining zeolite and blended at } 3 \text { for } 30 \mathrm{~s} \\
\text { Material was well blended with no Swheat buildup on } \\
\text { bottom }\end{array}$ \\
\hline Vol 11 & Wet/Low & 4.4 & $0.5^{\mathrm{a}}$ & $\begin{array}{l}\text { Added } 1 / 2 \text { zeolite and ran speed at } 8 \text { for } 10 \mathrm{~s} \text {, then } \\
\text { added remaining zeolite and blended at } 3 \text { for } 30 \mathrm{~s} \\
\text { Material was well blended with no Swheat buildup on } \\
\text { bottom }\end{array}$ \\
\hline Vol 12 & Moist/High & 4.4 & $0.5^{\mathrm{a}}$ & $\begin{array}{l}\text { Added } 1 / 2 \text { zeolite and ran speed at } 8 \text { for } 10 \mathrm{~s} \text {, then } \\
\text { added remaining zeolite and blended at } 3 \text { for } 30 \mathrm{~s} \\
\text { Material was well blended with no Swheat build up on } \\
\text { bottom }\end{array}$ \\
\hline$W L^{b} 13$ & WL & 4.4 & $0.5^{\mathrm{a}}$ & $\begin{array}{l}\text { Added } 1 / 2 \text { zeolite and ran speed at } 8 \text { for } 10 \mathrm{~s} \text {, then } \\
\text { added remaining zeolite and blended at } 3 \text { for } 30 \mathrm{~s} \\
\text { Material was well blended with layer of surrogate } \\
\text { buildup on bottom }\end{array}$ \\
\hline$W_{L}{ }^{b} 14$ & WL & 4.4 & $0.5^{\mathrm{a}}$ & $\begin{array}{l}\text { Added } 1 / 2 \text { zeolite and ran speed at } 8 \text { for } 10 \mathrm{~s} \text {, then } \\
\text { added remaining zeolite and blended at } 3 \text { for } 30 \mathrm{~s} \\
\text { Material was well blended with layer of surrogate } \\
\text { buildup on bottom }\end{array}$ \\
\hline
\end{tabular}

a Maximized volume in mixing bowl

${ }^{\mathrm{b}} \mathrm{WL}=$ Waste Lock 770

Initial tests (Moist 1-3) with moist/low salt surrogate waste produced a well-blended product after the zeolite was added all at once. Zeolite addition ratios of 2:1 to 4:1 (zeolite:RNS waste surrogate) by volume were evaluated. Blending for a minute on speed setting 3 effectively blended the Swheat into the zeolite matrix for the first three tests. The amount of zeolite added did not have a noticeable impact on the effectiveness of mixing the Swheat and salt into the zeolite matrix. When the bowl was emptied, an approximately 0.25 -in. layer was stuck on the bottom third of the bowl, did not appear to be blended, and was primarily red Swheat.

Two changes were made for the fourth test (Moist 4) zeolite was added in two steps: half was added and the mix speed was raised to speed setting 8 for 10 seconds, then reset to speed setting 3 and the remaining zeolite was added. The change was effective at eliminating the bottom layer. When material adhered to the side, it was well blended when it was dumped, not a layer of pure Swheat. 
Conditions for Moist 4 were then used on dry and wet surrogates. Tests Dry 5 and Wet 6 produced a wellblended product and were blended under the same conditions as Moist 4. A Swheat layer was not found on the bottom of the bowl for either test.

Test Dry 8 and Wet 9 evaluated a shorter blend time for the zeolite addition. These tests had mix times of $30 \mathrm{~s}$ for zeolite, once all of the zeolite was added.

Tests Vol 10 and Vol 12 focused on maximizing the available volume in the bowl. The bowl has maximum capacity of 8-qt, and a 6-qt batch size was used for these tests. A range of RNS surrogates were used to verify performance with the larger volume. The surrogate used in the tests did impact the overall moistness of the final product, but the resulting material was well blended and the zeolite addition method eliminated layering of the Swheat on the bottom of the bowl.

Step 1 conditions for zeolite addition tests: (Vol 10 through Vol 12)

- $\quad$ RNS waste-to-water volume ratio: 1:0.65

$$
\begin{aligned}
& * 1.75 \text { qt of surrogate waste } \\
& * \quad 1.15 \text { qt of water }
\end{aligned}
$$

- Mixer speed setting: 4

- Blend duration: 3 min

Figure 6 shows product from Vol 10 test. The red surrogate Swheat material appears well blended into the zeolite matrix and no salt crystals are visible, although upon very close examination small, fine particles can be identified.

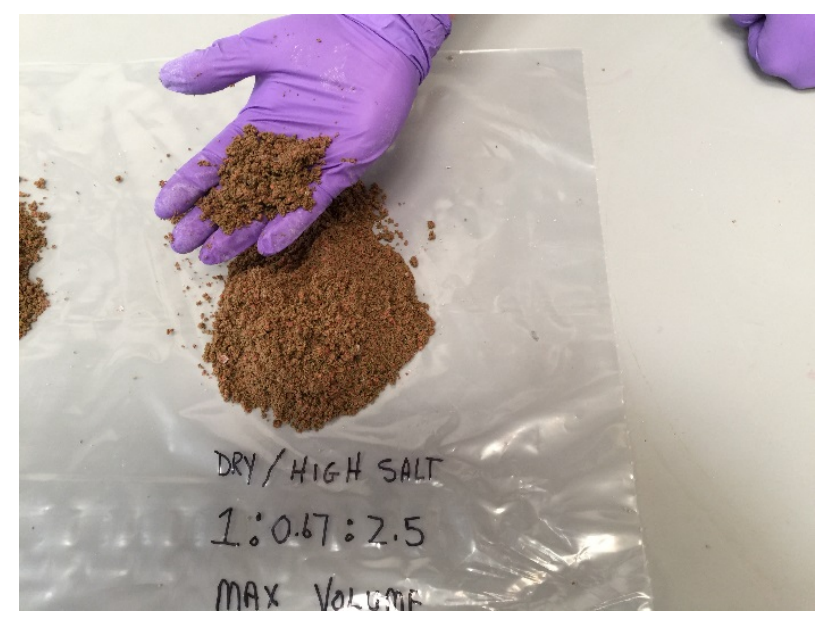

Figure 6. Final blended product from Test Vol 10

Two tests were performed to examine blending of salt coated with Waste Lock 770 . Waste Lock 770 is found in three drums. Surrogate material was prepared by mixing 1 volume of salt with 0.1 volume of water and 3 volumes of Waste Lock 770.

The same Step 1 recipe and conditions used for tests Vol 10 and Vol 12 were followed for the Waste Lock 770 tests, WL 13 and WL 14. The surrogate Waste Lock 770 material produced after Step 1 is shown in Figure 7 . The surrogate waste was gelatinous, and it was difficult to determine salt dissolution. The gelatinous material provided a wet coating around the salt crystals. 


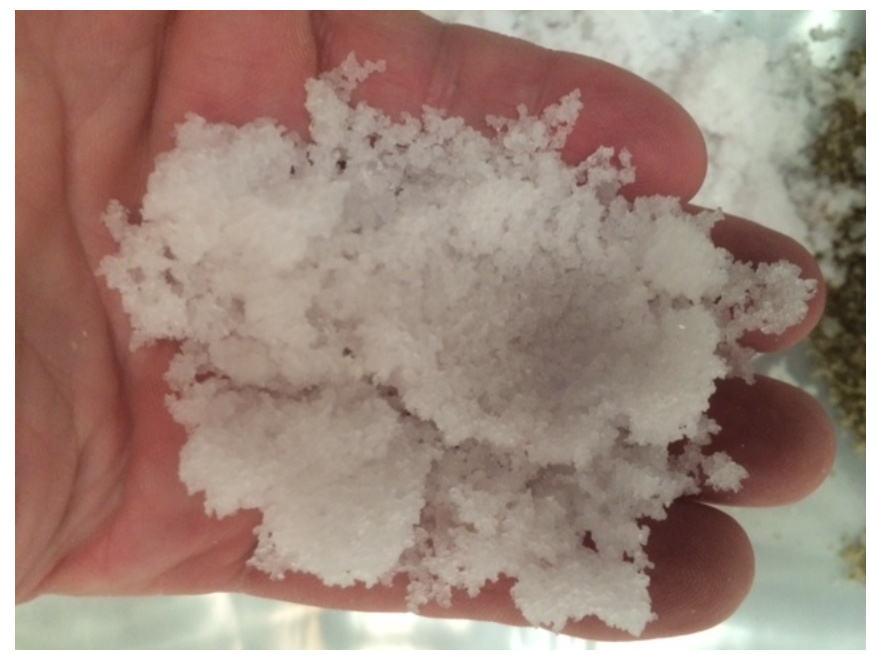

Figure 7 Surrogate Waste Lock 770 and salt (3:1 volume ratio)

The zeolite mixed well with the gelatinous Waste Lock 770 surrogate material produced in Step1. A total of 4.4 qt of zeolite was added and blended in a similar manner as previous tests. The product shown in Figure 8 is well blended, fluffy, and drier in appearance than comparable samples of product that contains Swheat. The mixer bowl was nearly full, but the contents did not spill out during the 30 -s blend. When the bowl was emptied, a layer of material was observed at the bottom of the bowl that was primarily the white surrogate waste material. Further testing with Waste Lock 770 continued to result in a thin layer of unmixed material at the bottom of the bowl.

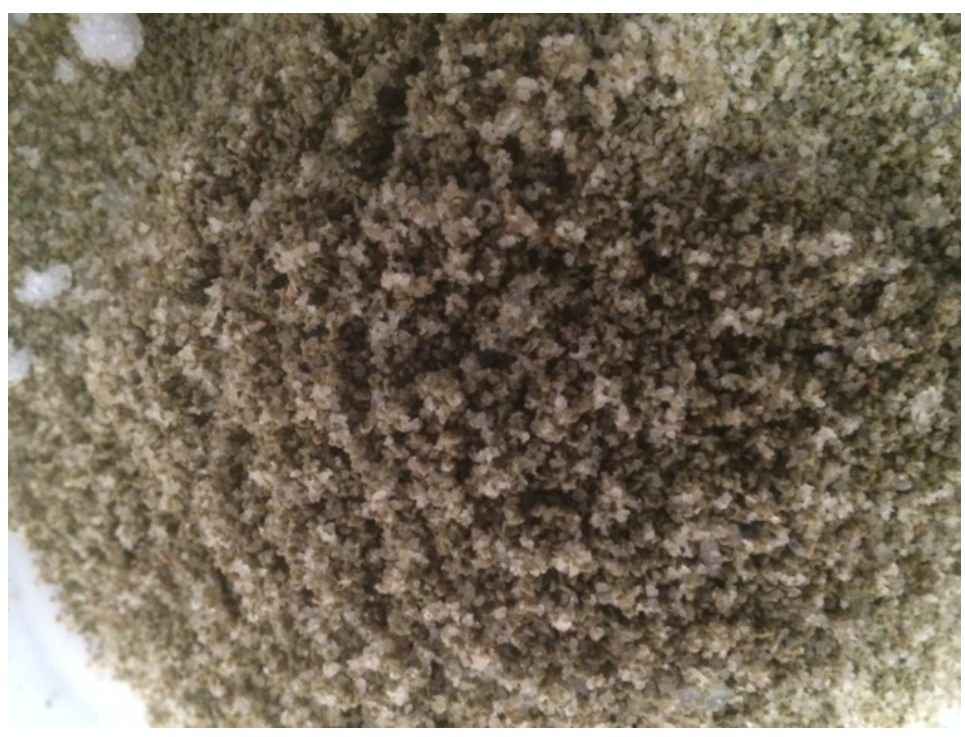

Figure 8 Waste Lock 770 surrogate waste blended with zeolite (Test WL 13) 


\subsection{CONCLUSIONS/RECOMMENDATIONS}

- The Kitchen Aid 8-qt model blender effectively blends a range of surrogate Swheat/salt and Waste Lock $770 /$ salt material into the zeolite.

- The effectiveness of the blending is not related to the wetness of the materials or the salt content of the surrogates at the blend ratios tested.

- Dissolution of salt into water requires about $3 \mathrm{~min}$, and the amount of water is related to the amount and type of salt found in the waste. The amount of water and required mix time will be determined after SWRI tests results are reviewed.

- A three-step approach was effective at dissolving most of the surrogate salt material and blending the resulting Swheat or Waste Lock 770 into the zeolite.

- Optimal blend ratios pending results from SWRI are

1. RNS waste-to-water volume minimum ratio: 1:0.65

2. RNS waste-to-zeolite volume minimum ratio: 1:2.5

- The recommended RNS waste process steps, pending SWRI tests results, are as follows:

1. Add 1.15 qt warm $\left(\sim 100^{\circ} \mathrm{F}\right)$ water to bowl

2. Add 1.75 qt RNS waste

3. Blend on speed setting 4 for 3 min

4. Add 2.20 qt of zeolite

5. Blend on speed setting 8 for $10 \mathrm{~s}$

6. Reduce speed to setting 3

7. Add 2.20 qt of zeolite

8. Blend for $30 \mathrm{~s}$

- Filling the bowl with 6 qt of material results in material spilling over the sides of the bowl. Three bowl modifications are recommended:

1. Modify the bowl to include a wider diameter rim around the top

2. Fabricate a cover that can be easily attached and removed to prevent material from spilling over the side of the bowl during blending

3. Lead-line the exterior of the bowl and the lid to limit radiation exposure to workers 
- Volumetric containers for water and RNS waste should be designed and fabricated once the final optimum recipe has been tested at SWRI. The containers should

1. be fabricated from a denser material or have lead lining for RNS material and have lids that will help reduce the radiation exposure to workers, and

2. be of a specific volume to eliminate the potential to incorrectly measure ingredients for blending

- Zeolite should be premeasured according to the volume required for each batch and placed in bags that could be loaded into the daughter drum for feeding the operation in the glovebox. As the RNS waste is blended, the bags can be used for adding zeolite to the blending operation.

Full-scale testing of the process should be done in a mock-up glovebox that simulates the WCRRF glovebox and use waste drums that simulate the RNS drum configuration. 